\title{
Negative Chemotaxis to Ammonia and Other Weak Bases by Migrating Slugs of the Cellular Slime Moulds
}

\author{
By TAITIRO KOSUGI† AND KEI INOUYE* \\ Department of Botany, Faculty of Science, Kyoto University, Kyoto 606, Japan
}

(Received 7 December 1988; revised 20 February 1989; accepted 3 March 1989)

\begin{abstract}
Ammonia is known to be a repellent gas for rising sorogens of Dictyostelium discoideum, and it has been suggested that it is also a repellent gas for migrating slugs of the same species. Here we present evidence that migrating slugs of $D$. discoideum and two related species, $D$. mucoroides and Polysphondylium violaceum, indeed orient away from high concentrations of $\mathrm{NH}_{3}$. In D. discoideum, brief exposure of a slug to an $\mathrm{NH}_{3}$ gradient of about 1 p.p.m. $\mathrm{mm}^{-1}\left(10^{-5} \mathrm{~atm}\right.$ $\mathrm{cm}^{-1}$ or $0.00076 \mathrm{mmHg} \mathrm{mm}^{-1}$ ) was sufficient to alter the direction of its migration. The gases of other weak bases, such as methylamine, trimethylamine, ethylamine and pyrrolidine, were also effective.
\end{abstract}

\section{INTRODUCTION}

The typical natural habitat of the dictyostelid slime moulds is soil (reviewed in Bonner, 1967; Raper, 1984). Although their behaviour in the natural environment has not been observed, simulation experiments in the laboratory show that at least the asexual developmental cycle of some dictyostelids proceeds essentially in the same manner in the soil as under ordinary laboratory conditions (Higuchi et al., 1983; K. Inouye, unpublished observations).

The behaviour of the pseudoplasmodium, or 'slug' (the precursor structure of the fruiting body), is generally thought to have significant effects on the survival and dispersal of the spores. For example, migrating slugs of most species are oriented by light and by a temperature gradient in such a way that they would tend to migrate towards the soil surface where they would fruit, thus ensuring seemingly optimal conditions for spore dispersal (Bonner et al., 1950, 1985; Whitaker \& Poff, 1980). It has been reported that slugs of Dictyostelium discoideum are also oriented by 'slug turning factor', a diffusible metabolite produced by slug cells (Fisher et al., 1981). However, since slugs in their natural habitats most probably move around in a tiny space surrounded by soil particles, the possibility arises that the course of slug migration is also affected by gaseous substances, which would diffuse much less quickly under such circumstances than in the open air.

To examine the effects of gases on slug orientation, we have tried to observe the behaviour of migrating slugs placed in a concentration gradient of various gases. However, because of the general difficulty in building up stable concentration gradients of gases and also in verifying the existence of the gradients, we will restrict the scope of this report to experiments using weak bases such as ammonia. Taking advantage of their extremely high solubilities in water, we were able to build up gradients of these gases by using a point source of the gas and an agar plate as sink. Such gradients lasted for a sufficiently long time, and could be visualized with appropriate $\mathrm{pH}$ indicators. The results clearly show that migrating slugs of $D$. discoideum orient away from all the weak bases that have been tested.

$\dagger$ Present address: Laboratory of Applied Botany, Faculty of Agriculture, Kyoto University, Kyoto 606, Japan. 


\section{METHODS}

Organisms and culture conditions. Wild-type strains of Polysphondylium violaceum (strain no. 6), Dictyostelium mucoroides $(\mathrm{H}-1)$ and $D$. discoideum (NC4 and V12M2) were used. Cells grown on Klebsiella aerogenes on a modified SM medium (Inouye, $1988 b$ ) were collected and washed in $20 \mathrm{mM}$-potassium phosphate buffer, pH 6.0 (PB), by repeated centrifugation. All incubations were conducted at $22{ }^{\circ} \mathrm{C}$.

Plate method. Agar plates were prepared by pouring $8 \mathrm{ml}$ molten agar (in distilled water containing $0.01 \%$ phenol red) into $9 \mathrm{~cm}$ diameter plastic Petri dishes. Thick suspensions $(10 \mu \mathrm{l})$ of washed cells (about $1.6 \times 10^{8}$ cells $\mathrm{ml}^{-1}$ in $\mathrm{PB}$ supplemented with $2 \mathrm{mM}-\mathrm{MgSO}_{4}$ ) were deposited at a position $1 \mathrm{~cm}$ from the centre of each agar plate. After the cells had settled on the agar substratum, excess fluid was removed. The plates were then placed in a light box so that unilateral light came in from the opposite side of the cell deposit (with respect to the centre of the plate). Within a day of deposition the plated cells aggregate to form slugs, which subsequently migrated away from the original cell deposits towards the light source. An Eppendorf tube $(0.4 \mathrm{ml})$ with a hole (diameter $1 \mathrm{~mm})$ in its side was then placed in each plate as a gas source so that the hole was positioned $3 \mathrm{~cm}$ from the centre in a direction perpendicular to the light direction (Fig. 1 a). The tube contained either $\mathrm{H}_{2} \mathrm{O}$ or $1 \mathrm{M}-\mathrm{NaOH}(200 \mu \mathrm{l})$ with various amounts of $\mathrm{NH}_{4} \mathrm{Cl}$ or trimethylamine hydrochloride. Care was taken that the liquid in the tube did not leak onto the agar surface. The plates, now carrying migrating slugs and a gas source, were then sealed with Parafilm, placed in a light-tight metal can, and incubated for another $24 \mathrm{~h}$. After this incubation period, the plates were opened up, the gradation of the colour of each plate recorded, and the slugs observed using a dissecting microscope. The slime tracks left behind by the slugs were then transferred onto round polyethylene sheets, which were subsequently stained with Coomassie blue solution $(0.3 \%$ in ethanol/acetic acid/water, $5: 1: 4$, by vol.) for permanent records (Fisher et al., 1981).

The 'orientation index' $(I)$ was defined as

$$
I=\frac{n_{+}-n_{-}}{n_{+}+n_{-}}
$$

where $n_{+}$and $n_{-}$denote the numbers of slugs found in the nearer side of the plate to the source and in the distant side from the source, respectively. Those which remained in the central zone (width $1 \mathrm{~cm}$ for Dictyostelium, $0.5 \mathrm{~cm}$ for Polysphondylium) were not included.

Micropipette method. Thick suspensions of washed vegetative cells were streaked on plain agar plates and incubated in the dark. Next day, a small agar block (about $2 \times 3 \times 1 \mathrm{~mm}$ ) carrying a migrating slug (normally about $1 \mathrm{~mm}$ long, for all three species used) was cut out from the plate and placed near the centre of a freshly prepared plain agar plate. The lid of the plate was replaced with another lid with a hole and a piece of wet filter paper attached inside. The plate was then put on the stage of an inverted microscope (Nikon TMD), and the movement of the slug was recorded using a high-sensitivity TV-camera (National WV-1850) and a timelapse videotape recorder (National NV-8030 or AG-6011). A glass micropipette filled with $\mathrm{NH}_{3}$ solution $(0 \cdot 1-10 \%$, w/v) was introduced into the plate through the hole so that its tip was positioned about $100 \mu \mathrm{m}$ above the agar surface and at various horizontal distances from the anterior region of the slug (Fig. 2). For accurate measurement of the angles, slugs migrating flat on the agar surface were used. It was assumed that the magnitude of the $\mathrm{NH}_{3}$ gradient was proportional to the concentration of $\mathrm{NH}_{3}$ solution in the micropipette and to the cross-section of its tip. In the experiments designed to eliminate the influence of substratum $\mathrm{pH}$, slugs on the agar blocks were allowed to migrate further so that their tips extended beyond the edge of the agar blocks. A micropipette filled with the gas source was introduced when more than a quarter of the length of the slug protruded from the edge of the agar block
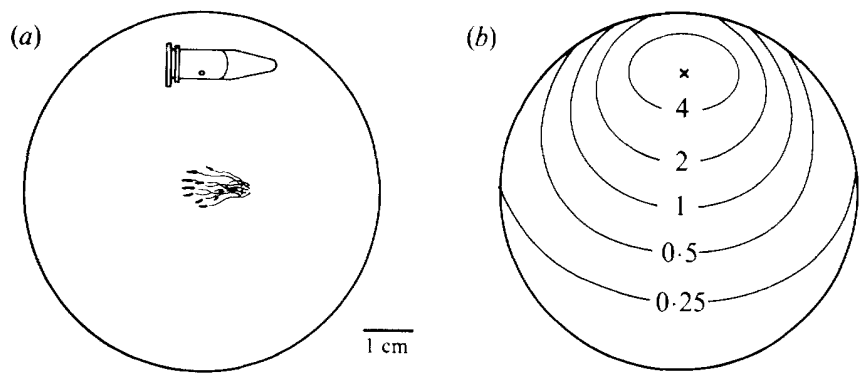

Fig. 1. The plate method. (a) Schematic representation showing the stage when an Eppendorf tube containing $\mathrm{NH}_{3}$-generating solution has just been put in place. (b) A concentration profile of $\mathrm{NH}_{3}$ gas at $8 \mathrm{~h}$ after setting up the $\mathrm{NH}_{3}$ source as shown in $(a)$; the concentration of $\mathrm{NH}_{3}$ at different points is given in p.p.m. $\left(10^{-6} \mathrm{~atm}\right)$. 


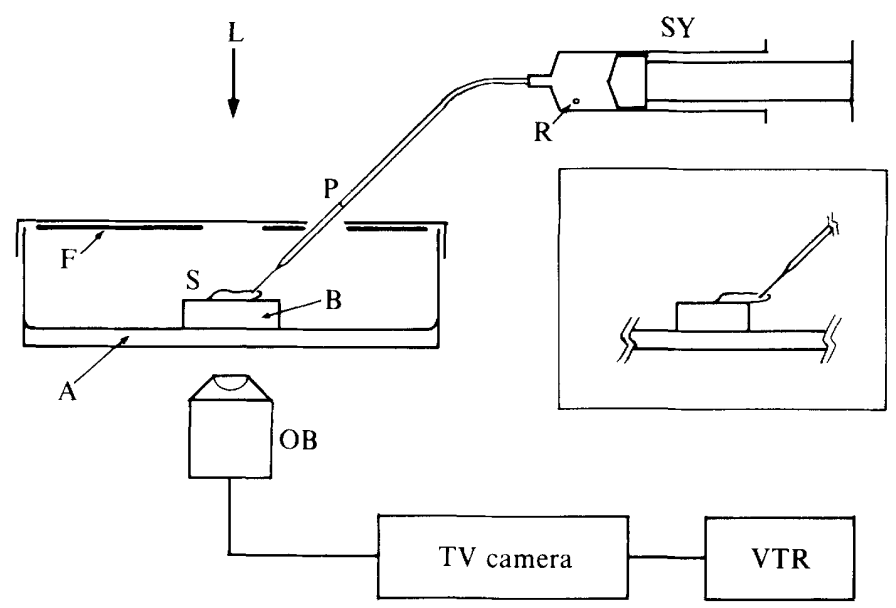

Fig. 2. Schematic representation of the micropipette method. L, red light for observation; SY, $2.5 \mathrm{ml}$ syringe; $R$, release (a hole of $0.5 \mathrm{~mm}$ diameter) for preventing flows of gas or liquid through the tip; $\mathrm{P}$, glass micropipette; F, wet filter paper; S, slug; B, agar block; A, agar plate; OB, objective (normally $\times 10$ ), VTR, videotape recorder. A manipulator holding the micropipette is omitted in the figure.

(Fig. 2, inset). The gas was considered to be a repellent if the slug kept advancing but the direction of its migration had deviated from its original direction away from the micropipette by at least $30^{\circ}$ after a period of $15 \mathrm{~min}$.

The glass micropipettes were made of pyrex glass tubing ( $1 \mathrm{~mm}$ outer diameter) using a vertical electrode puller (Narishige) and a pipette-tip grinder (Chatani). The inner diameter of the tips of the micropipettes used was 13-20 $\mu \mathrm{m}$.

Since slugs of the cellular slime moulds show strong phototaxis but are relatively unresponsive to red light of wavelength over $600 \mathrm{~nm}$ (Francis 1964; Poff et al., 1973), very weak red light was used for observation and videorecording to minimize any effect of light. The light source was a halogen microscope lamp and red light was selected with sharp cut-off filters $(610 \mathrm{~nm}$ ) made of acrylic board (total thickness $8 \mathrm{~mm}$ ); light intensity was further cut down with a neutral filter $(\times 16)$. Since the image was hardly visible through the oculars, a TV-monitor screened with a red acrylic board was used for observation. When room illumination was needed for handling the plates and micropipettes, a photographic red light bulb was used.

Calibration of $\mathrm{NH}_{3}$ concentration. For the plate method, the gradient of the phenol red colour (yellow to red) of each plate was recorded at the end of the experiments. The colour before introducing the source was yellow throughout the plate except for the central region (where the slugs were migrating), which showed a reddish tint. The colours were compared with standard colours made by injecting a known amount of $\mathrm{NH}_{3}$ gas into tissue culture flasks $(60.0 \mathrm{ml})$ containing $3.0 \mathrm{ml}$ phenol red agar (' $\mathrm{NH}_{3}$-standard flasks'). To verify the $\mathrm{NH}_{3}$ gradient in the air, 57 small pieces of wet $\mathrm{pH}$-indicator paper (cresol red, $3.5 \times 3.5 \mathrm{~mm}$ with $2.5 \mu \mathrm{l}$ distilled water) were attached at the lattice points $(1 \mathrm{~cm}$ period) of the underside of the lids of Petri dishes $(9 \mathrm{~cm})$. The lids were then placed on agar plates containing $\mathrm{NH}_{3}$ sources prepared in exactly the same way as in the chemotaxis experiments. The colour of the $\mathrm{pH}$-paper at various times was compared with the standard colours. The partial pressure of $\mathrm{NH}_{3}$ ( $p$ ) in the ' $\mathrm{NH}_{3}$-standard flasks' was calculated from the solubility constant of $\mathrm{NH}_{3}$ in water and the $\mathrm{pH}$ values, using the formula

$$
p=\frac{0 \cdot 0112}{1+10^{(9 \cdot 38-\mathrm{pH})}} \times\left[\mathrm{NH}_{3}+\mathrm{NH}_{4}^{+}\right]_{\text {in solution }}
$$

where $p$ is in atm and ammonia concentration in $\mathrm{mol}^{-1}$ (Denmead et al., 1982). The $\mathrm{pH}$ values of the agar in the ' $\mathrm{NH}_{3}$-standard flasks' were determined using 'pH-standard flasks' which had been made by including buffer at various $\mathrm{pH}$ values $(6 \cdot 0-11 \cdot 6)$ in phenol red agar. As an example, a concentration profile of $\mathrm{NH}_{3}$ at $8 \mathrm{~h}$ after the introduction of the $\mathrm{NH}_{3}$ source estimated by this method is shown in Fig. $1(b)$.

For the micropipette method, a micropipette filled with $10 \% \mathrm{NH}_{3}$ solution was placed $100 \mu \mathrm{m}$ above the surface of the phenol red $(0.02 \%)$ agar $(3.0 \mathrm{ml})$ made up in a tissue culture flask $(60.0 \mathrm{ml}$, with a hole) placed on the inverted microscope, and photographs were taken at intervals with a constant voltage. Green light was selected with a band pass filter $(509-562 \mathrm{~nm})$. The $\mathrm{pH}$ of the agar at various distances from the pipette tip at increasing times after its introduction was determined by measuring the absorbance of the negatives of the photographs. A 

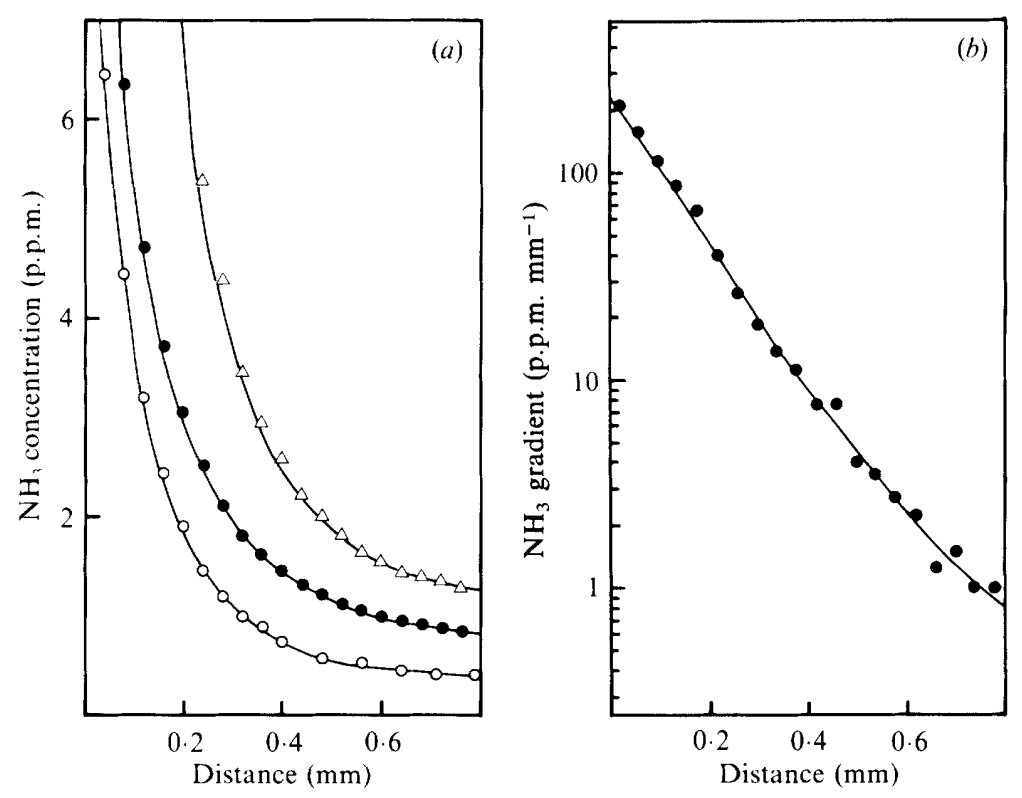

Fig. 3. Concentration profiles of $\mathrm{NH}_{3}$ gas. (a) Profile produced by a micropipette filled with $10 \%(\mathrm{w} / \mathrm{v})$ $\mathrm{NH}_{3}$ solution. The distance is that measured from the point on the agar surface immediately beneath the tip. Concentration profiles at $1 \mathrm{~min}(\mathrm{O}), 3 \mathrm{~min}(\mathrm{O})$, and $6 \mathrm{~min}(\triangle)$ after the introduction of the pipette are shown. (b) Magnitude of the $\mathrm{NH}_{3}$ gradient after 6 min at different points from the pipette tip. Differences between pairs of consecutive points in $(a)$ were divided by the distance between the points $(40 \mu \mathrm{m})$.

standard curve was constructed by measuring the absorbance of the negatives of the ' $\mathrm{NH}_{3}$-standard flasks' and the 'pH-standard flasks' (see above). A microscope equipped with a photometer (Reichert) was used for the measurements of absorbance. The area of measurement at each point was a circle of diameter $200 \mu \mathrm{m}$ on the negative (corresponding to $8 \mu \mathrm{m}$ in the real scale). Fig. 3(a) shows profiles of $\mathrm{NH}_{3}$ gas concentrations measured in this way at 1,3 , and 6 min after the introduction of a micropipette filled with $10 \% \mathrm{NH}_{3}$ solution, and Fig. $3(b)$ the dependence of the gradient of $\mathrm{NH}_{3}$ concentration on the distance from the pipette tip measured at $6 \mathrm{~min}$.

\section{RESULTS}

\section{Chemotaxis observed with a population of slugs (plate method)}

Chemotactic response of migrating slugs. When an $\mathrm{NH}_{3}$ source was placed at one end of a plate carrying migrating slugs and the plate incubated in the dark, there was an obvious tendency for the slugs to orient towards the opposite side of the plate. This was the case for all three species (four strains) of dictyostelid examined. Trimethylamine, another gaseous weak base, was equally effective. Fig. 4 shows an example of such an experiment for $D$. discoideum NC4, in which the slime tracks of slugs migrating in a control plate and in a plate containing an $\mathrm{NH}_{3}$ source are shown. To quantify this tendency, we used an 'orientation index', $I$ (see Methods). Fig. 5 shows the results of experiments, which, by the use of this index, clearly indicate the above tendency.

An alternative method to quantify the direction of chemotaxis in $D$. discoideum made use of the pulsatile nature of slug migration in this species. Often, but not always, $D$. discoideum slugs migrate in such a way that their tips continue to advance in the air to the extent that almost the whole slug is supported only at its rearmost part until it falls down in an indeterminate direction to resume migration (Inouye \& Takeuchi, 1979). Consequently, the track of such a slug is more or less zigzag. Since most of the slug body is in the air immediately before falling down, it is reasonable to assume that the gradient of the gas, if it is a repellent or an attractant, would affect 


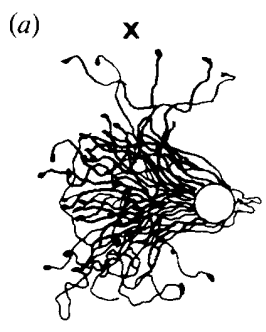

(b)

$\mathbf{x}$

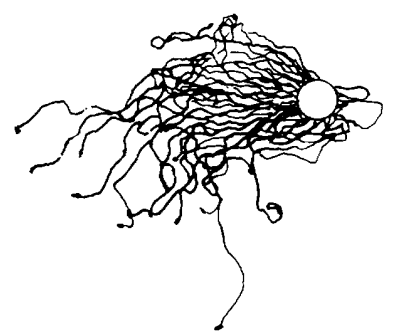

$1 \mathrm{~cm}$

Fig. 4. Slime tracks obtained with the plate method. (a) Control $\left(1 \mathrm{M}-\mathrm{NaOH}\right.$ without $\left.\mathrm{NH}_{4} \mathrm{Cl}\right),($ b) 20 mM- $\mathrm{NH}_{3}\left(1 \mathrm{M}-\mathrm{NaOH}\right.$ with $\left.4 \mu \mathrm{mol} \mathrm{NH}_{4} \mathrm{Cl}\right)$. The positions of the gas sources are indicated by a cross. The orientation index, $I$, was 0.13 for $(a)$ and -0.57 for $(b)$.

the direction of falling. We concluded therefore that the number of turnings towards and away from the gas source could be a good measure for the taxis. Measurements were made only for a few plates that showed very clear zigzag tracks. It was found that $67 \%$ and $89 \%$ of the turns seen in $\mathrm{NH}_{3}$ plates with 2.0 and $0.2 \mu \mathrm{mol} \mathrm{NH}_{3}$ in the source solution, respectively, were in the direction away from the source, while only $53-57 \%$ were away from the source for the $\mathrm{NH}_{3}$ plates containing less than $0.02 \mu \mathrm{mol} \mathrm{NH}_{3}$.

Visualization of $\mathrm{NH}_{3}$ gradients. Gradients of $\mathrm{NH}_{3}$ and other weak bases were visualized by including phenol red in the agar. That the gradients were produced by the gradient of $\mathrm{NH}_{3}$ gas existing in the air was verified by the use of many small pieces of $\mathrm{pH}$-indicator paper (cresol red) attached to the underside of the lid of the Petri dishes (see Methods). With this method, it was possible to observe the gradual spreading of $\mathrm{NH}_{3}$ gas to form a concentration gradient in the air (Fig. $1 b$ ). The $\mathrm{NH}_{3}$ gradient around the centre of a plate that showed negative chemotaxis was estimated to be around $0 \cdot 1$ p.p.m. $\mathrm{mm}^{-1}\left(10^{-6} \mathrm{~atm} \mathrm{~cm}{ }^{-1}\right)$ at $8 \mathrm{~h}$ after the introduction of an $\mathrm{NH}_{3}$

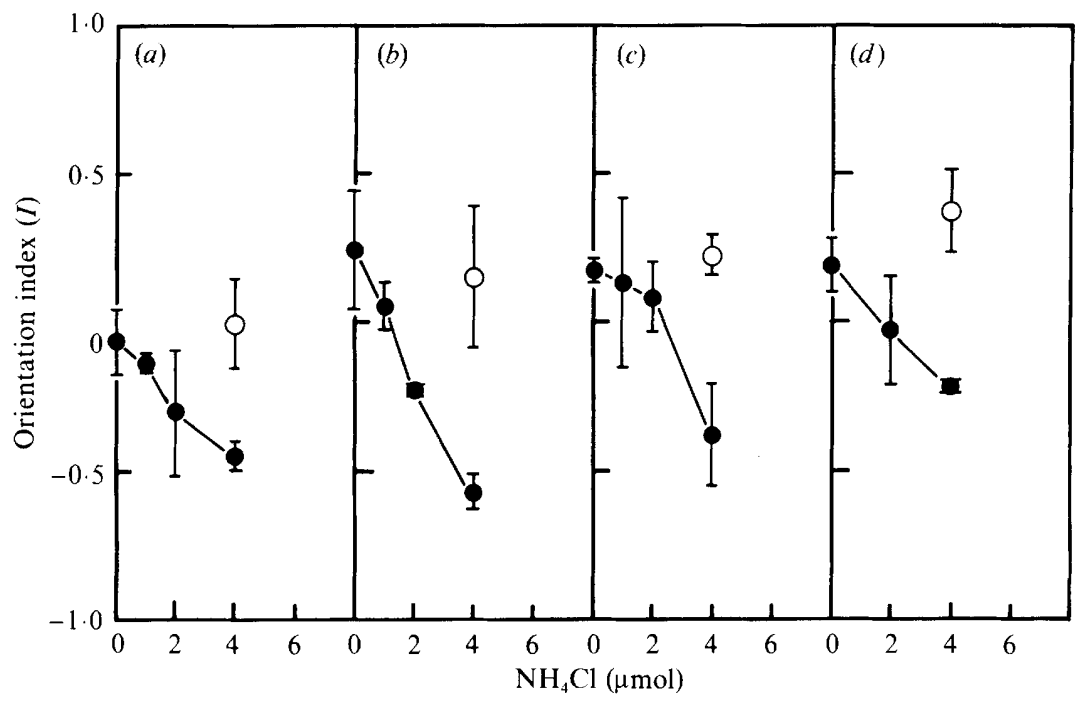

Fig. 5. Chemotaxis of migrating slugs represented by the orientation index. (a) $P$. violaceum, (b) D. mucoroides, (c) D. discoideum $\mathrm{NC4},($ d) D. discoideum V12M2. The gas source was $200 \mu 11 \mathrm{M}-\mathrm{NaOH}$ (O) or $200 \mu \mathrm{l} \mathrm{H}_{2} \mathrm{O}(\mathrm{O})$ containing the amount of $\mathrm{NH}_{4} \mathrm{Cl}$ indicated. Each point represents the mean of two to four experiments involving 31-117 slugs. Bars indicate $80 \%$ confidence intervals. 
source when the gradient reached a maximum. It is noteworthy that a small gradient still existed at $16 \mathrm{~h}$.

Possibility of pH-taxis. Raper (1939) and, more convincingly, Bonner et al. (1985) have shown that $D$. discoideum slugs tend to move towards the acid side of a $\mathrm{pH}$ gradient in the substratum. In our experiments, $\mathrm{pH}$ gradients always arose due to dissolution of the weak bases. Therefore one might imagine that the $\mathrm{pH}$ gradient resulting from the dissolution of the $\mathrm{NH}_{3}$ could have been the cause of the taxis of the slugs. This possibility is unlikely because the course of slug migration was little affected $(I=0.02 \pm 0.15$ for $D$. discoideum $\mathrm{V} 12 \mathrm{M} 2)$ by a pH gradient of the non-volatile base $\mathrm{KOH}$ approximately equal in magnitude to the greatest $\mathrm{pH}$ gradient produced by $\mathrm{NH}_{3}$ gas, namely about $0.2 \mathrm{pH}$ unit $\mathrm{cm}^{-1}$ around $\mathrm{pH} 8$ at the centre of the plate at $8 \mathrm{~h}$. This is in agreement with the results of Bonner et al. (1985), who estimated that a $\mathrm{pH}$ gradient greater than $3 \mathrm{pH}$ units $\mathrm{cm}^{-1}$ is needed for significant chemotactic response of slugs. In addition, the inclusion of a buffer ( $10 \mathrm{~mm}$-phosphate, $\mathrm{pH} 7)$ in the agar, which substantially reduced and delayed the generation of a $\mathrm{pH}$ gradient, affected the chemotactic responses of slugs only very slightly (about $6 \%$ reduction in the absolute value of $I$ ). Buffer was not included in the standard condition because it shortened the migration period of the slugs. The direct involvement of the gases in slug chemotaxis was further verified in the experiments using a glass micropipette as a gas source described in the following section.

\section{Chemotaxis observed with single slugs (micropipette method)}

Chemotactic responses in slugs to various weak bases. To demonstrate the effect of a concentration gradient of the gases more directly, we observed the behaviour of individual slugs in a concentration gradient of various gases. Glass micropipettes were used as the gas source. To minimize the possible effect of a $\mathrm{pH}$ gradient on slug behaviour, we applied a gradient of the weak bases to the aerial part of the slug (Fig. 2, inset; see Methods). Fig. 6 shows an example of

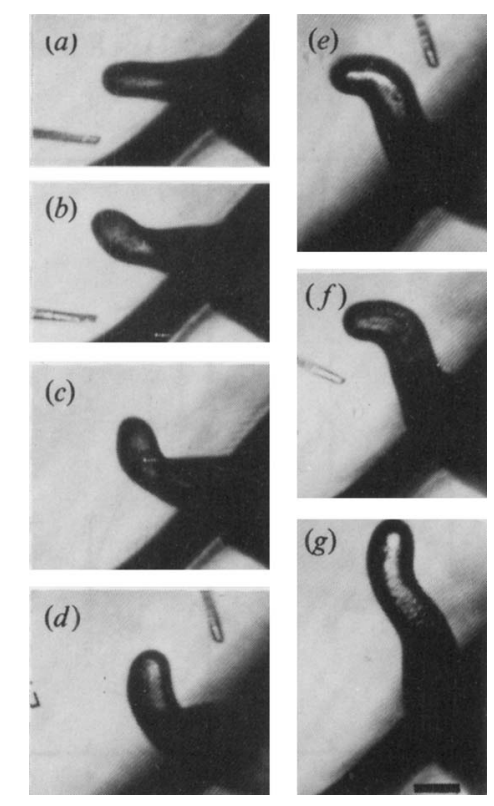

Fig. 6. Repeated turns by a $D$. discoideum slug induced by alternating the direction of a gradient of ethylamine. The anterior region of the slug extends in the air from the agar block which is seen in the lower right corner of each photograph (see Fig. 2 inset). The gas source was a glass micropipette containing $3 \%(\mathrm{w} / \mathrm{v})$ ethylamine solution. The tip diameter is $13 \mu \mathrm{m} .(a) 0 \mathrm{~min},(b) 3 \mathrm{~min},(c) 4.7 \mathrm{~min},(d)$ $8.4 \mathrm{~min},(e) 15.4 \mathrm{~min},(f) 17 \mathrm{~min},(g) 27.3 \mathrm{~min}$. Bar, $0.1 \mathrm{~mm}$. 

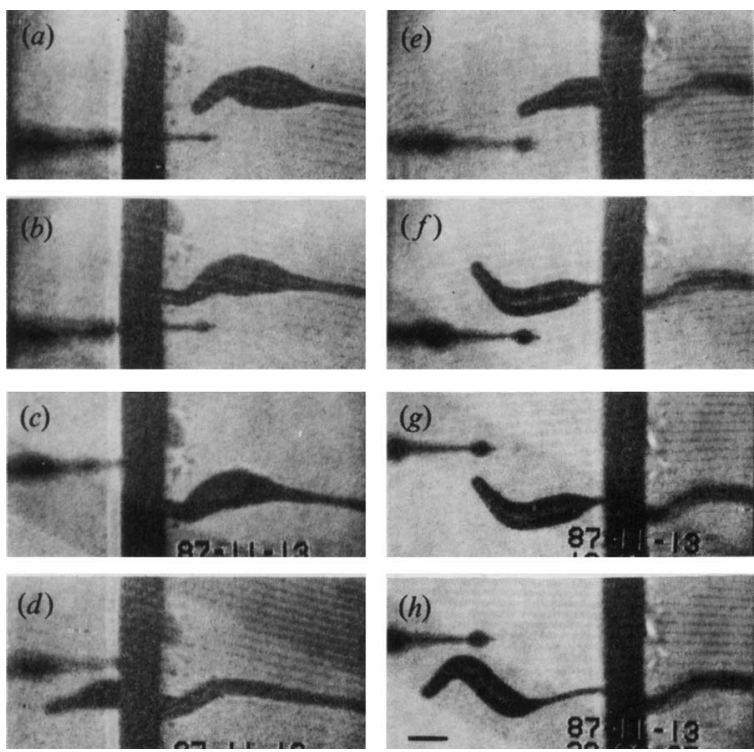

Fig. 7. Repeated turns of a $P$. violaceum slug. The vertical dark line seen in the middle of each photograph is the edge of the agar block on which the slug had been sitting. The slug is completely in the air in $(f)-(h)$. The water condensed on the micropipette near the tip did not obturate the tip opening. The micropipette contained $10 \%(\mathrm{v} / \mathrm{v}) \mathrm{NH}_{3}$ gas. (a) $0 \mathrm{~min},(b) 11 \mathrm{~min},(c) 19.2 \mathrm{~min},(d) 60 \mathrm{~min},(e)$ $62.7 \mathrm{~min},(f) 80.8 \mathrm{~min},(g) 81.2 \mathrm{~min},(h) 98 \mathrm{~min}$. Bar, $0.1 \mathrm{~mm}$.

Table 1. Effect of various weak bases on the orientation of migrating slugs of $P$. violaceum, D. mucoroides and D. discoideum

Micropipettes containing dilute $\mathrm{NH}_{3}$ gas $(1 \cdot 0-10 \%, \mathrm{w} / \mathrm{v})$ or aqueous solutions $(3-40 \%, \mathrm{v} / \mathrm{v})$ of other weak bases were used as gas source (see Fig. 2 inset). Deviation of orientation of slugs was measured after $15 \mathrm{~min}$.

\begin{tabular}{lccc}
\cline { 2 - 4 } $\begin{array}{c}\text { Number of slugs } \\
\text { Seviation } \\
\text { towards } \\
\text { source }\left(>30^{\circ}\right)\end{array}$ & $\begin{array}{c}\text { No } \\
\text { deviation } \\
\left(<30^{\circ}\right)\end{array}$ & $\begin{array}{c}\text { Deviation } \\
\text { away from } \\
\text { source }\left(>30^{\circ}\right)\end{array}$ \\
$\begin{array}{l}\text { P. violaceum } \\
\text { Air }\end{array}$ & 0 & 4 & 0 \\
Ammonia & 0 & 0 & 7 \\
Trimethylamine & 0 & 1 & 4 \\
D. mucoroides & & 3 & 0 \\
Air & 0 & 0 & 10 \\
Ammonia & 0 & 8 & 3 \\
D. discoideum & & 1 & 14 \\
Air & 0 & 1 & 5 \\
Ammonia & 0 & 0 & 5 \\
Methylamine & 0 & 1 & 5 \\
Trimethylamine & 0 & & \\
Ethylamine & 0 & & \\
Pyrrolidine & 0 & &
\end{tabular}

such an experiment with a $D$. discoideum slug. As shown in these photographs, it was often possible to make the slugs repeat right and left turns by alternating the position of the gas source. Such alternating turns in the air could be induced many times with $D$. mucoroides and $P$. violaceum because the slugs of these species can migrate in the air for a long period by virtue of the fact that stalk is continuously formed during migration (Fig. 7). 

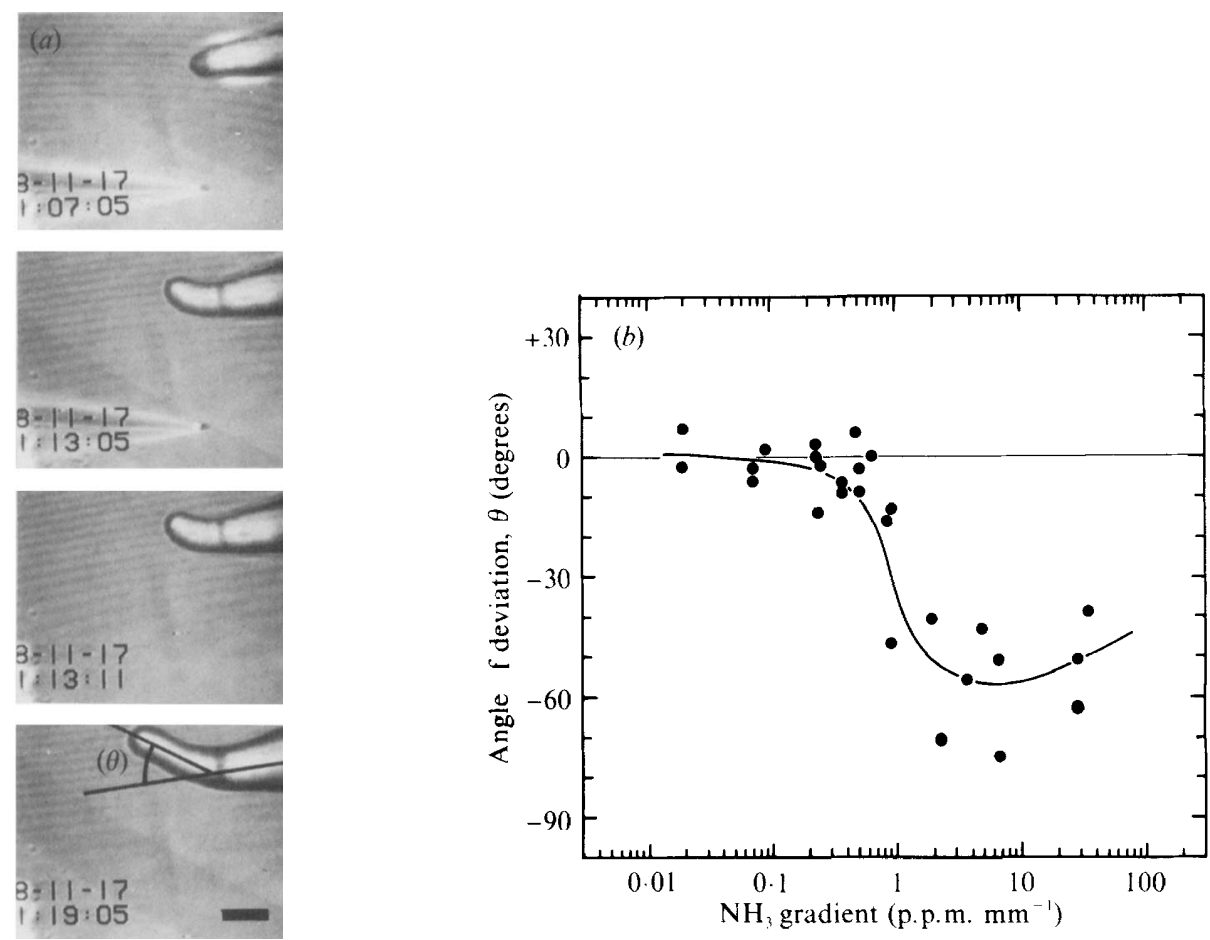

Fig. 8. Chemotactic responses of migrating slugs of $D$. discoideum (NC4) to $\mathrm{NH}_{3}$ gradients of various magnitudes. A micropipette filled with $\mathrm{NH}_{3}$ solution was introduced at $t=0 \mathrm{~min}$ and removed at $t=6 \mathrm{~min}$. The angles between the directions of the slugs at $t=0 \mathrm{~min}$ and at $t=12 \mathrm{~min}$ were measured (a) and related to the $\mathrm{NH}_{3}$ gradients at $t=6 \mathrm{~min}(b)$. In $(a)$, the $\mathrm{NH}_{3}$ gradient around the slug tip at $t=6$ min was 6.6 p.p.m. $\mathrm{mm}^{-1}$. The time is shown in the lower left corner of each photograph in $\mathrm{min}: \mathrm{s}$; bar, $0.1 \mathrm{~mm}$.

Several gaseous and volatile weak bases were examined using this method. Table 1 summarizes the results. It is evident that migrating slugs of $D$. discoideum showed negative chemotaxis to all the weak bases tested.

Chemotaxis with different $\mathrm{NH}_{3}$ gradients. To estimate the magnitude of the $\mathrm{NH}_{3}$ gradient sufficient to elicit a significant turn of migrating slugs, we measured the angles of deviation of the course of migration of slugs over a $12 \mathrm{~min}$ period induced by a brief exposure to various magnitudes of $\mathrm{NH}_{3}$ gradient. The magnitude of the $\mathrm{NH}_{3}$ gradient was determined separately by measuring the $\mathrm{pH}$ of the agar plate (see Fig. 3). As shown in Fig. 8, half-maximal response was observed at approximately 1 p.p.m. $\mathrm{mm}^{-1}\left(10^{-5} \mathrm{~atm} \mathrm{~cm}^{-1}\right)$.

\section{DISCUSSION}

This work was started with a view to searching for volatile or gaseous substances that are chemotactic for migrating slugs of the cellular slime moulds. In preliminary tests, the only gas that elicited unequivocal chemotactic responses was $\mathrm{NH}_{3}$. Therefore we concentrated on $\mathrm{NH}_{3}$ and related compounds for further study.

The relationship between $\mathrm{NH}_{3}$ and slug migration has been examined by Bonner and his coworkers. Having shown that migrating slugs of $D$. discoideum orient away from the alkaline side of a $\mathrm{pH}$ gradient, Bonner et al. (1985) suggested that the effect of the $\mathrm{pH}$ gradient might be mediated by a local difference in $\mathrm{NH}_{3}$ concentration due to a different extent of ionization of the 
$\mathrm{NH}_{3}$ molecules produced by the slugs. This proposal has since been strengthened by the findings that rising sorogens of $D$. discoideum orient away from high concentrations of $\mathrm{NH}_{3}$ (Bonner $e t$ al., 1986; Feit \& Sollitto, 1987) and that slugs migrate faster in a uniform atmosphere of $\mathrm{NH}_{3}$ (Bonner et al., 1988). The present study not only confirms the proposal that $\mathrm{NH}_{3}$ is a repellent gas for migrating slugs but also establishes the minimum $\mathrm{NH}_{3}$ gradient required.

It was found in this study that slugs orient away not only from $\mathrm{NH}_{3}$ but also from other weak bases. The possibility therefore arises that the effects of $\mathrm{NH}_{3}$, and of the other weak bases, are mediated by a rise in cytoplasmic $\mathrm{pH}\left(\mathrm{pH}_{\mathrm{i}}\right)$, because these weak bases elevate the $\mathrm{pH}_{\mathrm{i}}$ of dissociated slug cells (Inouye, 1988a; and unpublished observations). It is also possible that a rise in the $\mathrm{pH}$ of some intracellular vesicles (Yamamoto \& Takeuchi, 1983) is involved in the transduction of the weak base effect.

From the ecological point of view, the negative chemotaxis to $\mathrm{NH}_{3}$ may have important functions in the production and dispersal of spores. As Bonner et al. (1985) have suggested, it may help the slugs move towards the soil surface, just as phototaxis and thermotaxis are thought to do. We would further suggest that the amount of $\mathrm{NH}_{3}$ produced by a slug itself, estimated to be of the order of $10^{-13}-10^{-12} \mathrm{~mol} \mathrm{~min}{ }^{-1}$ for a medium-sized slug consisting of $10^{4}$ cells (see Sussman et al., 1977; Bonner et al., 1988), is large enough to guide the slug towards a more open space in the soil. For instance, 1 p.p.m. $\mathrm{NH}_{3}$ contains only about $4 \times 10^{-14} \mathrm{~mol} \mathrm{NH}_{3}$ in $1 \mathrm{~mm}^{3}$, and an $\mathrm{NH}_{3}$ gradient of 1 p.p.m. $\mathrm{mm}^{-1}$ was shown in this study to be sufficient for a significant chemotactic response of the slug. In addition, since $\mathrm{NH}_{3}$ has an inhibitory effect on the transition from slug to fruiting body (Schindler \& Sussman, 1977), the avoidance by slugs of high concentrations of $\mathrm{NH}_{3}$ would lessen the risk of their failing to form fruiting bodies. It should also be noted that a decrease in ambient $\mathrm{NH}_{3}$ concentration induces fruiting (Schindler \& Sussman, 1977 ; Inouye, 1988 b). Finally, slugs formed in a single amoebal population will be encouraged to disperse by the negative $\mathrm{NH}_{3}$ taxis. As discussed above, the amount of $\mathrm{NH}_{3}$ produced by a single slug will be sufficient to affect the course of migration of nearby slugs, and this will cause mutual repulsion of slugs. In preliminary experiments, we found that migrating slugs of D. discoideum repel each other (unpublished observations).

In summary, migrating slugs of some cellular slime mould species show negative chemotaxis to ammonia gas, and it is suggested that this may have important functions in the ecology of these organisms.

Some preliminary experiments were carried out by undergraduate students of Kyoto University, K. Nakamura, M. Huruse, H. Takeda, M. Kumagai, T. Nakaue, T. Yosinaga, Y. Yusa and H. Mizuhara, who participated in a 3 week laboratory course organized by K.I. in the past few years. The method of visualizing an $\mathrm{NH}_{3}$ gradient by the use of $\mathrm{pH}$-indicator paper was also developed during this course. We gratefully acknowledge their unfailing cooperation. We also thank Professor J. T. Bonner of Princeton University for his interest and encouragement.

\section{REFERENCES}

Bonner, J. T. (1967). The Cellular Slime Molds, 2nd edn, pp. 1-205. Princeton, NJ : Princeton University Press.

Bonner, J. T., Clarke, W. W., Neely, C. L., JR \& SLIFKIN, M. K. (1950). The orientation to light and the extremely sensitive orientation to temperature gradients in the slime mold Dictyostelium discoideum. Journal of Cellular and Comparative Physiology 36, 149-158.

BonNer, J. T., HAY, A., JoHN, D. G. \& Suthers, H. B. (1985). pH affects fruiting and slug orientation in Dictyostelium discoideum. Journal of Embryology and Experimental Morphology 87, 207-213.

BonNer, J. T., Suthers, H. B. \& Odell, G. M. (1986). Ammonia orients cell masses and speeds up aggregating cells of slime moulds. Nature, London $\mathbf{3 2 3}$, 630-632.
Bonner, J. T., Chiang, A., Lee, J. \& Suthers, H. B. (1988). The possible role of ammonia in phototaxis of migrating slugs of Dictyostelium discoideum. Proceedings of the National Academy of Sciences of the United States of America 85, 3885-3887.

Denmead, O. T., Freney, J. R. \& Simpson, J. R. (1982). Dynamics of ammonia volatilization during furrow irrigation of maize. Soil Science Society of America Journal 46, 149-155.

FeIt, I. N. \& Sollitto, R. B. (1987). Ammonia is the gas used for the spacing of fruiting bodies in the cellular slime mold, Dictyostelium discoideum. Differentiation 33, 193-196.

Fisher, P. R., Smith, E. \& Williams, K. L. (1981). An extracellular chemical signal controlling phototactic behaviour by $D$. discoideum slugs. Cell $23,799-807$.

Francis, D. (1964). Some studies on phototaxis of 
Dictyostelium. Journal of Cellular and Comparative Physiology 63, 131-138.

Higuchi, G., IshiI, S. \& YamadA, T. (1983). Cinematographical studies of cellular slime molds. II. The migrating pseudoplasmodium on the soil. Development, Growth and Differentiation 25, 434 (abstract).

INOUYE, K. (1988a). Differences in cytoplasmic pH and the sensitivity to acid load between prespore cells and prestalk cells of Dictyostelium. Journal of Cell Science 91, 109-115.

INOUYE, K. $(1988 b)$. Induction by acid load of the maturation of prestalk cells in Dictyostelium discoideum. Development 104, 669-681.

INOUYE, K. \& TAKEUCHI, I. (1979). Analytical studies on migrating movement of the pseudoplasmodium of Dictyostelium discoideum. Protoplasma 99, 289-304.

Poff, K. L., Butler, W. L. \& Loomis, W. F., JR (1973). Light-induced absorbance changes associated with phototaxis in Dictyostelium. Proceedings of the National Academy of Sciences of the United States of America 70, 813-816.

RAPER, K. B. (1939). Influence of culture conditions upon the growth and development of Dictyostelium discoideum. Journal of Agricultural Research 58, 157198.

RAPER, K. B. (1984). The Dictyostelids, pp. 1-453. Princeton, NJ : Princeton University Press.

Schindler, J. \& Sussman, M. (1977). Ammonia determines the choice of morphogenetic pathways in Dictyostelium discoideum. Journal of Molecular Bio$\log y$ 116, 161-169.

Sussman, M., SCHINDler, J. \& KIM, H. (1977). Toward a biochemical definition of the morphogenetic fields in D. discoideum. In Development and Differentiation in the Cellular Slime Moulds, pp. 31-50. Edited by P. Cappuccinelli \& J. M. Ashworth. Amsterdam: Elsevier/North Holland.

Whitaker, B. D. \& PofF, K. L. (1980). Thermal adaptation of thermosensing and negative thermotaxis in Dictyostelium discoideum. Experimental Cell Research 128, 87-94.

Yамамото, A. \& TAKeUChi, I. (1983). Vital staining of autophagic vacuoles in differentiating cells of Dictyostelium discoideum. Differentiation 24, 83-87. 